\title{
On the Possibility of Presentism with Occurrents
}

\author{
Marco Marabello ${ }^{1}$
}

Received: 24 November 2020 / Revised: 21 January 2021 / Accepted: 24 January 2021 /

Published online: 20 March 2021

(c) The Author(s) 2021

\begin{abstract}
This paper defends the possibility of admitting occurrents in a presentist ontology. Two ways of doing so are proposed, the first one involves Meinongian presentism. By using the notion of non-existent object and coherently modifying some mereological principle, it is argued, the presentist can allow for occurrents. The second proposal involves ex-concrete objects. Ex-concrete objects, i.e. objects that are contingently not concrete, have been used by Linsky and Zalta (Philosophical Perspectives, 8 (Logic and Language), 431-458, 1994), Williamson (2002) in the modal metaphysics debate, by Orilia (Philosophical Studies, 173 (3), 589-607, 2016) in the presentism-eternalism debate, and by Longenecker (Synthese 195 (11), 5091-5111, 2018) in the debate about material constitution. I argue that, just by admitting exconcrete objects, it is possible to have occurrents even for the presentist. Of course, in order to do so we must modify our definitions of occurrent and continuant. Nevertheless, I argue that my theory is metaphysically sound, at least for the presentist persuaded by the intuitive claim that there are occurrents, which otherwise she must reject.
\end{abstract}

Keywords Presentism · Occurrents · Meinongianism $\cdot$ Ex concrete

\section{Introduction}

Two of the main theses in the metaphysics of time are eternalism and presentism. Eternalism holds that past, present and future are ontologically on a par. On this account, past, present and future entities equally exist. Just as from the mere fact that New York is about $5600 \mathrm{~km}$ from London does not follow that New York does not exist, so, from the fact that some events or entities are temporally distant from us, it does not follow that they do not exist. For the eternalist both the Roman Empire and space travel exist, and the universe is a "four-dimensional spatiotemporal manifold of events and objects-the so-called block universe" (Sider 2001, p. 11). On the other

Marco Marabello

marco.marabello@unine.ch

1 Institut de Philosophie, Université de Neuchâtel, Neuchâtel, Switzerland 
hand, presentism holds that only the present and present objects exist. Presentism is often considered as the common-sense view: we usually believe that dinosaurs do not exist anymore and that colonies on mars do not yet exist. ${ }^{1}$

On the other side, we have two different ways of persisting, where to persist is defined as existing (at least) at two different times. The first one is to persist by perduring: an entity perdures if and only if it persists by having temporal parts. Following Simons (2000), ${ }^{2}$ I call these entities occurrents. The second one is to persist by enduring: an entity endures if and only if it persists by being wholly present at each time at which it persists, or more straightforwardly an entity endures if it persists and does not have temporal parts. I call enduring entities continuants.

It would seem then that the two theories of time combined with the two ways of persisting can give us the four following different possibilities:

\section{Presentism with occurrents}

2. Presentism with continuants

3. Eternalism with occurrents

4. Eternalism with continuants

Now, usually, if one is an eternalist, she acknowledges the existence of occurrents. I suppose that almost every eternalist thinks that occurrents exist; however, disagreement arises on whether they should admit continuants in their ontology. For example, Haslanger (2003, p. 321) writes: "the issue is whether there are enduring things in addition to stages and worms." where enduring thing and worm mean respectively continuant and occurrent in our terminology. Thus, (4) is better spelled out as "eternalism with occurrents and continuants". ${ }^{3}$ On the other hand, almost ${ }^{4}$ every presentist allows for continuants; after all it seems the natural way to go if you hold, as the presentist does, that everything that exists exists at the present, unextended moment. It seems however that the possibility of having occurrents in a presentist framework is much more controversial than the parallel possibility, namely admitting continuants, for the eternalist.

The plan is as follows: in section $\S 2$, I will explain why a presentist might want occurrents in her ontology. In section $\$ 3$ I will analyze Merricks' argument against presentism and occurrents, I will consider a possible answer, which I will dismiss since it does not preserve our common understanding of occurrents. In section $\S 4$,

\footnotetext{
1 There has been much debate on how to properly understand the presentists' claim. However, I won't focus on the different characterizations of that claim and I assume that the standard formulation is clear enough for the purposes of this work.

2 Simons in turn follows Johnson in using these terms. See Simons (2000, p. 59).

3 An eternalist who also is a mereological nihilist, i.e. who holds that composition never occurs, might hold a version of eternalism with continuants but without occurrents. Moreover, an eternalist could hold what Costa (2017) calls simplism, that is, entities persist by being temporally extended simples. In this latter case, the eternalist denies both the existence of continuants and occurrents.

4 I suppose that some presentist could hold a stage view. For the stage viewer nothing really persists, and all the different stages are related by a temporal counterpart relation analogous to the modal one. See Sider (1996) and Varzi (2003) for examples of stage theorists.
} 
I will argue that, against Merricks, there are at least two ways to have occurrents while maintaining presentism. The first way makes use of non-existents, thus I propose a theory that I call Meinongian presentism with occurrents (MEPO). In section $\S 5$, I will propose a second possibility, which makes use of ex-concrete objects and following Koslicki (2006) and Paul (2002) allows for mereological sums of nonmaterial and material objects. In section $\S 6$, I will answer some objections to the view that I call ex-concrete presentism with occurrents (EXPO). A concluding section will follow.

\section{Why does the Presentist Need Occurrents?}

Before discussing a way to make room for occurrents in our presentist's world, we should provide some reasons, hopefully good, to do so. In this section, I will sketch some reasons for admitting occurrents in a presentist ontology.

Brogaard (2000) argues that presentism provides a solution to the no-change argument that the eternalist who loves occurrents faces. For the perdurantist, things change by having different temporal parts bearing incompatible properties. The classic example is that of Socrates' sitting and Socrates' standing. The temporal part of Socrates at $t_{1}$ (Socrates-at- $t_{1}$ ) is seating, while the temporal part of Socrates at $t_{2}$ (Socrates-at- $t_{2}$ ) is standing. However, the no-change objection holds that this is not real change but mere replacement because the two incompatible properties are not instantiated by the same substratum (Simons, 2000, p. 65). Thus, Brogaard finds a way to avoid the objection by endorsing presentism, for presentism provides 'real' change by means of the coming into existence and the going out existence of each temporal part. Nevertheless, what Brogaard does is to provide a reason to endorse presentism for the occurrents' lover, whereas what we are looking for is a reason for the presentist to admit occurrents in her ontology.

Someone might say that the presentist does not have any reason to add occurrents in her ontology. Taking ontological parsimony as a virtue of our theory, this philosopher might say that continuants are enough. However, theories must find a balance between ontological parsimony and explanatory power, and we might be justified in adding the category of occurrents in our ontological catalogue, because the resulting theory could explain more than its ontologically lesser loaded antagonist. Lehmkuhl (2018) writes:

"[parsimony] is rather attractive philosophically. But, in the end, we don't know if the world is simple, and so we don't know if the simplest approach gives the best possible fit to the world. [...] it may turn out that operating with only one kind of screwdriver limits you in how you can handle the actual world." (Lehmkuhl 2018, p. 30)

Indeed, it seems that if continuants are our only kind of screwdriver, we are left with plenty of screws that we don't know how to handle. Our world is filled with occurrents, events most notably. How can we give reason of events within a presentist framework? We might say even that "one might be forgiven for 
thinking with Moore that anything so obvious should be a datum of philosophy, a starting point, rather than a belief to be defended." (Simons 2000, p. 61). I suppose that the presentist has at least four possibilities here: first, she can explain how events are not really occurrents but continuants, namely she has to reduce them to continuants; second, she might hold a view such as that defended in Prior (1962), that is, she might be eliminitavist about events; third, she might endorse some deflationist account of events à la Kim (1966); fourth, she can consider them as legitimate in her ontology. The first possibility entails that all events are punctual and unextended in time. ${ }^{6}$ But this seems implausible: most of the events around us are not punctual. Consider the paradigmatic case of a football match. It is composed by the first half and the second half separated by a fifteen minutes break in between. ${ }^{7}$ The second possibility is to follow Prior (1962). Prior in his Changes in Events and Changes in Things argues that talk about events is just a more complicated way of talking about things. That is, there really are no events but just objects (Prior, 1968, pp. 10-11). Nevertheless, it seems that to be eliminativists regarding events would result in a highly revisionary ontology and we should try to avoid it. Moreover, this seems against the spirit of presentism, which is by large taken to be the "common sense" view (Markosian, 2004). Now, it seems that there are events, in an ontological robust sense, is indeed another common sensical fact. Thus, adopting an ontology of events seems more in agreement with the presentist spirit.

However, it is indeed true that there are many deflationist accounts of events, ${ }^{8}$ and the presentist could endorse any one of them. Thus, the third and fourth possibilities seem to be equally appealing. I, for one, doubt that there might be a knockdown argument against a deflationary account of events and thus, in the remainder of this paper, I will just assume that the presentist might want to endorse a robust ontological conception of events and leave a defense of this statement to another time.

This should be enough to motivate presentism with occurrents. In the next section I will present the most notable argument against this view.

\section{Merricks' Argument}

The most prominent argument against occurrents and presentism is provided by Merricks (1995). Merricks argues that:

\footnotetext{
${ }^{5}$ Here Simons (2000) is arguing for the existence of continuants. Nevertheless, I believe that the same point applies to occurrents as well.

6 This move might be considered similar to what the eternalist who admits only occurrents in her ontology does. The presentist here considers everything time-like unextended, whereas the eternalist occurrentist considers everything time-like extended.

7 The halftime break might be considered a temporal part of the match. However, another possibility is to consider the football match an intermittent occurrent. See Simons (2003).

${ }^{8}$ See Simons (2003, p. 65 and ff.) for an overview of different deflationist accounts and Orilia (2012) for a presentist solution to the problem of extended events.
} 
(1) Presentism entails that there are no occurrents, i.e. that there are no objects that persist by having temporal parts.

This claim is in turn grounded in the claim:

(2) "An object cannot have another object as a part if that other object does not exist" (Merricks 1995, p. 524).

Indeed, (2) seems very reasonable, and it is equivalent to a standard mereological principle, call it Axiom 0, that is: 'If something is a part, then it exists'. ${ }^{9}$ Moreover, Axiom 0 is commonly omitted because of its indisputability.

Consider now the main thesis about how occurrents persist for the eternalist:

(3) Occurrents persists by having different temporal parts which exist at different times.

(4) At most one temporal part exists at each instant of time.

If now we wear the presentist's goggles and suppose that:

(5) Presentism and occurrents are compatible.

It follows that:

(6) The parts that do not exist at the present time do not exist at all either.

If presentism is true, at most one part exists at the present moment and all the others do not exist. Therefore, either (2) or (5) must be rejected. But (2), according to Merricks, is unimpeachable, and from (5) follows (6) which is in contradiction with (2). Therefore, we must reject (5) and conclude (1).

A response to Merricks' argument was given by Lombard (1999). Lombard argues that presentism with occurrents is perfectly compatible with the truth of (2). The reason to say so is that nothing about occurrents contradicts the truth of (2). Recall how occurrents persist: they persist by having different temporal parts at different times. Now, consider an object $x$, and its temporal part $x$-at- $t$; what exists at $t$ is just one of the temporal parts of $x$, namely $x$-at- $t$, and $x$-at- $t$ does not have at $t$ or at any other time some other non-existent temporal part of $x$. Thus, the core of the theory of occurrents together with presentism does not contradict (2), or so Lombard argues. I find Lombard's reply unsatisfactory for one reason: it seems to misconstrue the perdurantist's claim. I do agree with Lombard that at any moment no temporal part of $x$ has another temporal part of $x$ as part, and

\footnotetext{
${ }^{9}$ Formalizing this principle in the standard first order language of mereology we obtain: $x<y \rightarrow E ! x \wedge E ! y$. Simons' axiom CTA8 holds that if: $x<_{t} y$, then $x$ exists at $t$ and $y$ exists at $t$ (Simons 1987 p. 179). Axiom 0, as I call it, is just CTA8 with parthood simpliciter and not temporary parthood.
} 
thus if the latter part is non-existent it is not part of the former. But in the "philosophy seminar', $x$ is the sum of its temporal parts, all of which exist tenselessly if we believe in eternalism. On the other hand, if we believe in presentism there cannot be an object such as $x$, because the only thing we have are just different temporal parts at different times. An occurrent would turn into a mere succession of temporal parts never making up a whole. But this is in contrast with our definition of occurrent: an occurrent is just a complex entity whose parts are temporal parts. Furthermore, this would entail that an occurrent is identical with each of its temporal parts, a statement, I suppose, that an occurrents' friend would strongly deny.

Thus, I conclude that without denying claim (2), occurrents turn out to be something different than what we would have wanted. Alternatively, we might want to modify our theory of occurrents in such a way to made it consistent with presentism, but the modifications should maintain the salient trait of the usual account, namely that to be an occurrent is to be a mereological sum, and Lombard's account falls short in this respect.

\section{Neo-Meinongianism to the Rescue}

In this section, I will try to sketch one answer to Merricks' argument. This answer rejects claim (2) above, namely the claim that for something to be a part, that something must exist. I will try to show that this answer is not as crazy as it might seem at first sight.

To begin with it seems that Merricks' claim (1) is false. His claim is charged with modal force, it has the modal force of a necessarily true statement. It should therefore be impossible, metaphysically impossible, to have presentism with occurrents. However, this seems too strong. Indeed, extending presentism in a way to accommodate (a kind of) occurrents is possible. I believe that the presentist has at least two possibilities here. Let's start with the first one, which is probably the most controversial of the two.

The first possibility ahead of the presentist involves Meinongianism. ${ }^{10}$ Although the debate on Meinongianism is a lively one, it is not my purpose here to defend it. My aim is instead to open conceptual space for the presentist, and Meinongianism seems to be an available, and I believe powerful, weapon in the arsenal of the presentist. $^{11}$

Roughly, Meinongianism is the view for which there are things that do not exist, usually called non-existent (Van Inwagen 2008). Classical examples of non-existents are fictional characters, e.g. Sherlock Holmes, Gandalf, Harry Potter etc.... Another kind of non-existents are past entities, e.g. Julius Caesar,

\footnotetext{
${ }^{10}$ I use the term Meinongianism to refer to a view that is more properly called neo-Meinongianism.

${ }^{11}$ See, for instance, Paoletti (2016)'s recent treatment of Meinongian presentism and Hinchliff (1988)'s unrestricted presentism.
} 
J.F.K. etc.... Sure, Meinongianism comes in many kinds, and not all of them are committed to the non-existence of past entities, ${ }^{12}$ but nevertheless some Meinongians can accept this. Of course, talking about non-existent past entities makes sense only within a presentists' framework: as it should already be clear, for the eternalist Julius Caesar and J.F.K. exist, full stop. Now, what could an occurrent be for the Meinongian presentist? Well, under this view, an occurrent is just a sum of non-existent parts with one existent part. Consider again a nonpunctual event, an event that usually is understood as extended through time, say a football game. For the standard presentist, extended events are impossible. But for the Meinongian presentist they are possible, they persist as occurrents and therefore they have temporal parts. Thus, an extended ${ }^{13}$ event is just the sum of an existing temporal part, that part corresponding to the present time, with many non-existent parts, those corresponding to past and future ${ }^{14}$ times. The football game at minute $m$ is composed by the part of the game at minute $m$, the existing present part, and the parts of the game at minutes earlier or later than $m$, which are non-existing. More precisely, following Sider (2001, p. 60)'s standard definition of temporal parts, we can define a new kind of temporal part, call it tempo$\operatorname{ral~part~}_{M}$

$x$ is a temporal $\operatorname{part}_{\mathrm{M}}$ of $y$ iff:

(ia) $x$ is a part of $y$;

(iia) $x$ exists at most at one instant $t$, and it is non-existent at all other instants;

(iiia) If $t$ is the (only) instant at which $x$ exists then $x$ overlaps every part of $y$ that exists at $t$.

It makes sense to define a new sense in which something is an occurrent for the Meinongian presentist, that is, a different way of defining what an occurrent is maintaining its salient trait, namely the partition into temporal parts:

\footnotetext{
${ }^{12}$ For example, Berto and Plebani (2015) write: “A Meinongian may accept that (purely) fictional objects like Sherlock Holmes are non-existent, for instance, but reject that past existents like Jefferson, Dante or Virgil should be seriously taken as non-existent objects at the present time." (Berto and Plebani 2015, p. 104).

13 The use of the term extended seems here unjustified, I will provide a characterization of what I mean with extended event in due course.

${ }^{14}$ This claim, that is whether to admit or not future non existents, is controversial even for the Meinongians (See Berto and Plebani 2015, p. 104). However, to make room for events within presentism, it seems enough to admit past non-existent entities.
} 
$X$ is an occurrent iff:

(ib) At any instant of time $t, X$ is composed by at least two temporal parts.

(iib) At any instant at most one of its temporal parts exists. ${ }^{15}$

(iiib) Each temporal part exists at most for one instant.

Thus, consider our paradigmatic example of occurrent, the football match. Under Meinongian presentism, at any instant $t_{l}$ of the football match, the football match is a sum of an existing temporal part, say match-at- $t_{1}$, and of many non-existing temporal parts, say match-at- $t_{n}$ with $n<1$ or $n>1$.

This view, which I call Meinongian presentism with occurrents (MEPO) might be considered bizarre, or even absurd. But it seems unfair to me. Consider the special composition question, i.e. under which conditions do some things compose a whole, and its most prominent answer, i.e. the thesis of unrestricted composition, that is: under every condition some parts make up a whole.

Given unrestricted composition, take any two objects whatsoever and you have a whole composed of those two objects. For example, take my right foot pinkie and the top of the Eiffel tower: those two objects compose a whole. Suppose now that the eternalist, who admits occurrents, is also a lover of unrestricted composition (as usually is the case). In this case, the eternalist is committed to mereological fusion between temporal parts. For example, the temporal part of Julius Caesar at a particular moment with one of my temporal parts, or the first half of the battle of Hastings with the temporal part of Donald Trump at the moment of his election as $45^{\text {th }}$ President of the United States. Indeed, strange fusions happen when we adopt unrestricted composition, but even stranger ones happen when we hold both eternalism (with or without occurrents) and unrestricted composition.

For the Meinongian, unrestricted composition might not be restricted to existing things. The Meinongian has in her pocket different quantifiers from the usual ones, call them $\Lambda$ and $\Sigma$ (Berto and Plebani 2015). $\Lambda$ stands for the universal quantifier, and $\Sigma$ for the particular one. The usual quantifiers are defined in terms of these two, plus the primitive ${ }^{16}$ existence predicate $E$ !. There should be no problem for the Meinongian in simply using her quantifiers in defining unrestricted composition. Thus, the usual axiom of unrestricted composition $\exists x \varphi x \rightarrow \exists z F \varphi z$, that says that "that for any formula or predicate $\varphi$, so long as there is something satisfying that formula, there is a fusion of all the things that satisfy it" (Varzi and Cotnoir in press, p. 30) would become $\Sigma x \varphi x \rightarrow \Sigma_{z} F \varphi z$.

\footnotetext{
15 There is no lower limit to the number of existing temporal parts. This means that an occurrent might have no existing temporal parts at all. I suppose this would be valued by the Meinongian, because it can distinguish between non existents occurrents (i.e. non-existent compounds of temporal parts) and nonexistent continuants.

${ }^{16}$ The existence predicate is for the Meinongian primitive and not defined with the use of the particular, and existentially loaded quantifier.
} 
The same goes for the already named Axiom 0 of mereology: $x<y \rightarrow E ! x \wedge E ! y$, where in this case $E !$ is not primitive but defined as $E ! x={ }_{d f} \exists y(y=x)$. Then, it should be possible to modify the axiom using the Meinongian quantifiers and thus admitting non-existent parts.

However, Benovsky (2009), for example, charges of metaphysical 'madness' a view that allows mereological sums of non-existents such as MEPO ${ }^{17}$ For him unrestricted composition is still restricted to existents and therefore acceptable, whereas Meinongian presentism is not. In his words:

"But however unrestricted, it certainly cannot be that unrestricted unrestricted mereological composition is restricted to existent things only, and any attempts to take away even this restriction would lead one to weird places where no sensible metaphysician (I hope) wants to go - like commitments to individuals made up of the top half of Sam's body today, and all of the tropical fish of the nineteenth century, and three unicorns, and two fire-breathing dragons." (Benovsky 2009, pp. 301-302)

In other words, the main reason to not accept Meinongian fusions is that there is a clear difference in allowing for complex objects made of parts existing at different times and allowing for complex objects made of parts, some of which are non-existents. Why should we consider this clear difference not relevant? The friend of unrestricted composition admits fusions with abstract objects as she admits fusions of objects existing at different times. Abstract objects are standardly considered as existent objects. Thus, the friend of unrestricted composition allows for sums of, e.g., the number one and my right foot pinkie. Furthermore, there seems to be no difference between the fusion of Julius Caesar and Donald Trump and the fusion of the number one and my right foot pinkie. Now, Meinongians à la Routley (1980) or à la Priest (2005) hold that abstract objects are nonexistents and that the only existent objects are those which possess causal powers. Therefore, for them fusions of abstract and concrete objects turn into fusions of existent and non-existent objects. If this is the case, then fusions with nonexistents should be regarded on the same level as fusions of abstract and concrete objects, and consequently on the same level as fusions of objects existing at different times.

Furthermore, consider the principle of composition as identity (CAI), which states that mereological sums are nothing over and above the parts that compose them, and thus they come as free lunch. Suppose that you are a Meinongian and thus, you believe in non-existents, and suppose also that you believe in CAI, then you get mereological sums of existents and non-existents for free, they are not something more to which you are committed: "It just is them. They just are it." (Lewis 1991, p.81).

\footnotetext{
17 Although he acknowledges that a Meinongian could have no problem to endorse exactly such thing.
} 
This is all regarding Meinongian presentism with occurrents. Indeed, a strange view, but nonetheless, I believe, certainly possible, and therefore, available to the presentist who wants to include events in her ontology.

But maybe there is a less strange view, something that does not involve non-existents as parts. Let's consider this alternative in the next section.

\section{Presentism and Ex-Concretes}

Although I defended MEPO as metaphysically sound, I acknowledge that its appeal to most of the metaphysical gourmets out there is null. Just at the word "Meinongian", scared crowds flee the theatre. Therefore, for those who have a metaphysical refined palate I propose a second theory.

This second theory does not reject claim (2), but instead use the notion of an exconcrete part and it maintains some of the salient traits of our common understanding of occurrents.

This approach involves ex-concrete or contingently non-concrete objects understood as Linsky and Zalta (1994) or Williamson (2002).

What are ex-concrete objects? They are not abstract objects because the property of being abstract, as it is usually conceived, is an essential property of the objects that bear it, that is they cannot fail to bear that property. Ex-concrete are objects that might be concrete, or, most relevantly to our case, are objects that had been concrete and now they are not. ${ }^{18}$ In Williamson's words:

"When Trajan died, he did not become an abstract object, although he ceased to be concrete. He did not become the value of some abstraction operator. He became something neither abstract nor concrete, but something that had once been concrete. Trajan is an ex-concrete object. Similarly, if my parents had never met, I would have been something neither abstract nor concrete, but something that could have been concrete. I would have been a possible concrete object. I would not have been a physical object, but I would have been a possible physical object." (Williamson 2002, p. 246)

If the presentist wishes to admit ex-concrete objects in her ontology, as for example Orilia (2016), then we can put forward the following proposal: temporal parts are ex-concrete. They are concrete at one instant and only at that instant. They are ex-concrete at any other instant. Following the standard definition of temporal parts provided by Sider (2001, p. 60), we can provide a definition for this new kind of temporal part, call it temporal part $_{E C}$ :

$x$ is a temporal part ${ }_{\mathrm{EC}}$ of $y$ iff:

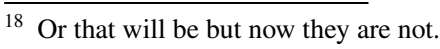


(ic) $x$ is a part of $y$;

(iic) $x$ is concrete at most at one instant $t$, and ex-concrete at all other instants;

(iiic) If $t$ is the (only) instant at which $x$ is concrete then $x$ overlaps every part of $y$ that exists at $t$.

Free from the ontological burden of non-existents we can now define occurrents in this way:

$X$ is an occurrent iff:

(id) At any instant of time $t, X$ is composed by at least two temporal parts.

(iid) At any instant at most one of its temporal parts is concrete. ${ }^{19}$

(iiid) Each temporal part is concrete at most for one instant.

Under this view, which I call ex-concrete presentism with occurrents (EXPO), an occurrent is just a complex object made up of ex-concrete temporal parts and at most one concrete temporal part. Thus, at any instant $t_{1}$ of our football match, the football match is a sum of a concrete temporal part, say match-at- $t_{1}$, and of many exconcrete temporal parts, say match-at- $t_{n}$ with $n<1$ or $n>1$.

EXPO has some clear advantages over MEPO described above. Firstly, it is important to notice that one who believes in ex-concrete objects does not believe in a plethora of Meinongian objects such as Pegasus, Harry Potter and the like. Meinongian presentism allows us to save occurrents but at the same time commits us to much more. Even if we don't consider round squares and golden mountains, the ontological burden of Meinongianism might be too much. On the other hand, endorsing ex-concrete objects does not require commitment to more ex-concretes than those we need.

Secondly, this is clearly compatible with Merricks' claim (2), and, consequently, with Axiom 0. Merricks' claim states just that an object cannot have as a part something that does not exist. However, it does not deny the possibility of parts which are non-material but nevertheless exist. EXPO holds that all the parts of an occurrent exist, they just do not belong to the same category: one is concrete, the others are ex-concrete.

Thirdly, the theory proposed has an advantage over Meinongian presentism, it does not stand alone in the philosophical landscape. In a certain sense, we could say that this view has pedigree. Indeed, the theory could fit in a class of theories that we might call non-material partism, following Longenecker (2018). Three examples of non-material partism are Laurie Paul's theory of logical parts, Kathrin Koslicki's neoAristotelian hylomorphism and, more recently, Michael Longenecker's non-concrete partism. Paul (2002) argues for a mereological bundle theory for which particulars are

\footnotetext{
19 There is no lower limit to the number of concrete temporal parts. This means that an occurrent might have no concrete temporal parts at all. This acknowledges the difference between a past occurrent, i.e. an occurrent that has only ex-concrete parts from occurrents that are now unfolding, i.e. occurrents with one concrete part.
} 
just mereological sums of properties. In her account, properties are parts of particulars, 'logical' parts in Paul's terminology. On the other hand, Koslicki (2008) proposes a neo-Aristotelian hylomorphic theory in which a matter/form compound has form as one of its parts. Structure, that plays the role of form in her theory, is just a part of an object together with its matter. Finally, Longenecker (2018) argues that his non-concrete partism allows to solve the problem of material constitution in a novel way. This latter view in particular makes use of ex-concrete or contingently non-concrete objects as EXPO does.

All these views, including the theory I proposed, are united by the same two problems, problems that are only apparent though. These problems go under the names of spatialism and categorialism (Longenecker 2018).

Spatialism can be summed by the slogan "parts lie within their wholes" (Gilmore 2006, p. 221). More precisely, given the definition of exact location:

Object $x$ is exactly located at a region $r$ if and only if $x$ and $r$ have "the same shape, size and boundaries" (Costa 2017, p. 59) and stand in the same spatiotemporal relations with other objects.

Then we can say that an intuitive principle is that:

$x$ 's parts are exactly located at a subregion of $x$ 's exact location. (spatialism)

It is clear that non-material partist theories experience some difficulties in this matter. Take for example EXPO, how can we say that the ex-concrete temporal parts of $x$ are (exactly) located at some subregion of the exact location of $x$ ? But as much as intuitive spatialism is, certainly it is not a metaphysical necessity. And the presentist who happens to be an occurrents' lover might well be motivated to abandon it.

On the other hand, categorialism, namely the fact that only entities of the same category can be relata of the parthood relation, might be appealing, but mereology as such does not commit us to this principle. As Lewis (1991, p. 76) puts it "mereology is silent" about this.

\section{Objections}

It is now time to consider some objections to EXPO. I will consider three objections, which I think are compelling. Some of these objections and the answers I propose apply equally to MEPO, but since I argued that EXPO has clear advantages over MEPO my talk about these objections will be restricted to EXPO.

\subsection{First Objection: Timely Extension}

I have provided a justification for introducing events in our ontology by saying that extended events are something that should be a 'datum of philosophy' and a 'starting point'. It seems, though, that under this view there are no extended events, for if occurrents are fusions of temporal parts, all of which, except one, are ex-concrete, it 
turns out that an event is not extended in time but at each moment at which it exists it has all of its temporal parts.

\subsection{Answer}

I propose to modify our common usage of the term temporally extended. To be temporally extended now means just having (non-concrete) temporal parts. Thus, a punctual event is an event that has no non-concrete temporal parts, whereas extended events are mereological compounds of non-concrete and concrete temporal parts.

\subsection{Second Objection: Ad Hocness of Ex-Concrete}

It might be argued that introducing ex-concrete is an ad hoc move to allow occurrents in our ontology.

\subsection{Answer}

This is false. Ex-concrete can fulfill multiple purposes in a presentist ontology. Orilia (2016), for example, uses ex-concrete in his moderate presentism. In his theory, ex-concretes are useful because they fulfill the purpose of being the referents of backward terms, namely terms like 'Caesar' or in our case 'the first half of the football match'. Ex-concrete objects, thus, allow the presentist to solve the problem of the reference of backward terms without resorting to "individual essences, thisnesses, haecceities, or the like, which many philosophers find too esoteric or otherwise problematic" (Orilia 2016, p. 592).

The problem of cross temporal relation is similar to the problem of backward terms; indeed, it is just the same matter under different circumstances. When we say, 'I am the grandson of George', but unfortunately grandpa 'George' passed away long ago, how can I enter in the relation of 'being-the-grandson-of' with a nonexistent thing? Sally Haslanger puts the problem like this: "One might object to this view by claiming that existing things cannot bear relations to non-existing things. However, if presentism is to be tenable at all, it must provide an account of statements that appear to assert cross-temporal relations" (Haslanger 2003, p. 324). It is clear that ex-concrete objects cope also with this problem. ${ }^{20}$ To bear a relation to a contingently non-concrete object seems much less problematic than to bear a relation to a non-existent. It seems therefore that the job for contingently non-concrete, or ex-concrete, entities is there.

${ }^{20}$ Indeed, Orilia (2016) uses ex-concretes also to solve this problem. 


\subsection{Third Objection: Continuants vs Occurrents}

It might be argued that, within the scope of my theory, the classical distinction between continuants and occurrents does not work. Usually, it is said that continuants persist by being wholly present at each time at which they exist, whereas occurrents persist by having different temporal parts at different times. Now, under my theory, occurrents are wholly present at each time at which they exist, it is just that some of their parts are non-concrete.

\subsection{Answer}

I propose a slight modification of the distinction between continuants and occurrents. 'Wholly present' is now relativized to concrete parts. Thus, continuants are wholly present because they have only concrete parts at each moment at which they exist. On the other hand, occurrents are not wholly present because they have parts other than those that are concrete.

\subsection{Fourth Objection}

One could hold the following principle, call it concreteness: all concrete complex entities have only concrete parts. If we applied it to an event such as our football match, which seems very much concrete, then all of its parts must be concrete. But the theory proposed denies that all of its parts are concrete and therefore, we should conclude that either the football match is not concrete or that the principle just stated is dispensable.

\subsection{Answer}

It seems to me that saying that the football match is not concrete would be too high a price for the views here defended. But rejecting concreteness seems warranted. I don't have a knockdown argument against concreteness, and I doubt there might even be one. However, this principle is commonly rejected. Consider, for example, Koslicki (2006)'s interpretation of Aristotle's hylomorphism. Koslicki argues that, according to Aristotle, the form is part of the matter/form compound. Now, the matter/form compound is clearly something concrete while form is not. Therefore, according to Koslicki's interpretation, Aristotle denies concreteness. Additionally, it seems that all the proponents of theories similar to EXPO, e.g. Paul (2002), Koslicki (2008), Longenecker (2018), must deny the principle of concreteness. Thus, EXPO in this respect, is not different from all those theories. 


\section{Conclusion}

In this paper I tried to defend the plausibility of a view that allows for occurrents in a presentist ontology. My purpose was to show that there are ways for the presentist to have occurrents. Although the two views that I presented modify our common understanding of occurrents, I believe that they maintain their main feature, namely that they are mereological fusions. This is the main advantage of my theory with respect to the solution proposed by Lombard. In fact, Lombard's understanding of occurrents together with presentism delivers just aggregates of temporal parts. Furthermore, the theory I proposed makes use of well-known and widely accepted notions in metaphysics. It fits within the so-called non-material partist theories that I believe are metaphysically firm. It makes use of ex-concrete objects, which the presentist might be forced to adopt anyway to solve various problems of her temporal ontology.

Therefore, it is a metaphysically sound theory for the presentist who is trying to have a dualism of continuants and occurrents.

Acknowledgements I am grateful to Franz Berto, Giovanni Buonocore, Alessandro Cecconi, Damiano Costa, Anna Marmodoro, Camille Neidhardt, Alberto Pasquetto, three anonymous referees, and the audience at ECAP 10 for their comments on earlier versions of this paper.

Funding Open Access funding provided by Université de Neuchâtel.

Data Availability Not applicable.

Code Availability Not applicable.

\section{Declarations}

Conflicts of Interest/Competing Interests Not applicable.

Open Access This article is licensed under a Creative Commons Attribution 4.0 International License, which permits use, sharing, adaptation, distribution and reproduction in any medium or format, as long as you give appropriate credit to the original author(s) and the source, provide a link to the Creative Commons licence, and indicate if changes were made. The images or other third party material in this article are included in the article's Creative Commons licence, unless indicated otherwise in a credit line to the material. If material is not included in the article's Creative Commons licence and your intended use is not permitted by statutory regulation or exceeds the permitted use, you will need to obtain permission directly from the copyright holder. To view a copy of this licence, visit http://creativecommons.org/licen ses/by/4.0/.

\section{References}

Benovsky, J. (2009). Presentism and persistence. Pacific Philosophical Quarterly, 90(3), 291-309.

Berto, F., \& Plebani, M. (2015). Ontology and metaontology. A contemporary guide. London: Bloomsbury Academic.

Brogaard, B. (2000). Presentist four-dimensionalism. The Monist, 83(3), 341-356.

Costa, D. (2017). The transcendentist theory of persistence. Journal of Philosophy, 114(2), 57-75.

Gilmore, C. (2006). Where in the relativistic world are we? Philosophical Perspectives, 20(1), 199-236. 
Haslanger, S. (2003). Persistence through time. In M. J. Loux \& Dean W. Zimmerman (Eds.), The Oxford handbook of metaphysics (pp. 315-354). Oxford: Oxford University Press.

Hinchliff, M. (1988). A defense of presentism. Doctoral dissertation, Princeton University.

Kim, J. (1966). On the psycho-physical identity theory. American Philosophical Quarterly, 3, $277-285$.

Koslicki, K. (2006). Aristotle's mereology and the status of form. Journal of Philosophy, 103(12), $715-736$.

Koslicki, K. (2008). The structure of objects. Oxford: Oxford University Press.

Lewis, D. K. (1991). Parts of classes. Oxford: Blackwell.

Lehmkuhl, D. (2018). The metaphysics of super-substantivalism. Noûs, 52(1), 24-46.

Linsky, B., \& Zalta, E. N. (1994). In defense of the simplest quantified modal logic. Philosophical Perspectives 8 (Logic and Language):431-458.

Lombard, L. B. (1999). On the alleged incompatibility of presentism and temporal parts. Philosophia, 27(1-2), 253-260.

Longenecker, M. (2018). Non-concrete parts of material objects. Synthese, 195(11), 5091-5111.

Markosian, N. (2004). A defense of presentism. Oxford Studies in Metaphysics, 1, 47-82.

Merricks, T. (1995). On the incompatibility of enduring and perduring entities. Mind, 104(415), 521-531.

Orilia, F. (2012). Dynamic events and presentism. Philosophical Studies, 160(3), 407-414.

Orilia, F. (2016). Moderate presentism. Philosophical Studies, 173(3), 589-607.

Paoletti, M. P. (2016). A sketch of (an actually serious) meinongian presentism. Metaphysica, 17(1), $1-18$.

Paul, L. A. (2002). Logical parts. Noûs, 36(4), 578-596.

Priest, G. (2005). Towards non-being. The logic and metaphysics of intentionality. Oxford: Oxford University Press.

Prior, A. N. (1962). Changes in events and changes in things. In A. N. Prior (Ed.) (1968), Papers on time and tense. Oxford: Oxford University Press.

Prior, A. N. (1968). Papers on time and tense. Oxford: Oxford University Press.

Routley, R. (1980). Exploring Meinong's Jungle and Beyond. Canberra: Australian National University, RSSS.

Sider, T. (1996). All the world's a stage. Australasian Journal of Philosophy, 74(3), 433-453.

Sider, T. (2001). Four dimensionalism: an ontology of persistence and time. Oxford: Oxford University Press.

Simons, P. (1987). Parts: a study in ontology. Oxford: Oxford University Press.

Simons, P. (2000). Continuants and occurrents. Aristotelian Society Supplementary, 74(1), 59-75.

Simons, P. (2003). Events. In M. J. Loux \& D. W. Zimmerman (Eds.), The Oxford handbook of metaphysics. Oxford: Oxford University Press.

Van Inwagen, P. (2008). McGinn on existence. Philosophical Quarterly, 58(230), 36-58.

Varzi, A., \& Cotnoir, A. (in press). Mereology. Oxford: Oxford University Press.

Varzi, A. (2003). Naming the stages. Dialectica, 57(4), 387-412.

Williamson, T. (2002). Necessary existents. Royal Institute of Philosophy Supplement, 51, 233-251.

Publisher's Note Springer Nature remains neutral with regard to jurisdictional claims in published maps and institutional affiliations. 